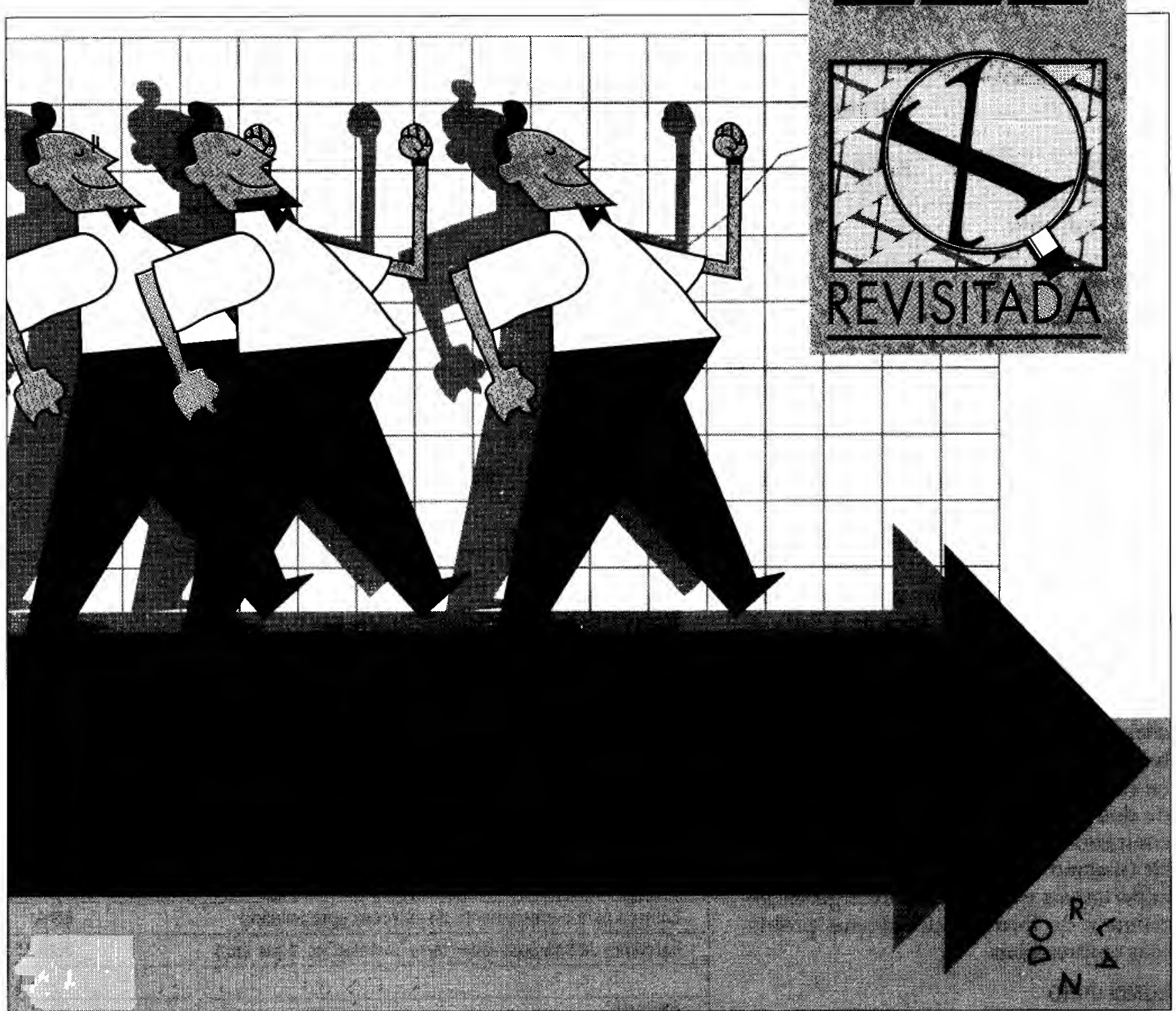

\title{
AS EMPRESAS E A TRANSMISSÃO DA IDEOLOGIA
}

Fernando C. Prestes Motta

Professor Titular do Departamento de Administração Geral e Recursos Humanos da EAESP/FGV.

* RESUMO: As organizações são conjuntos práticos voltados para a produção e para a reprodução de determinadas relações sociais necessárias à manutenção e à expansão do sistema econômico vigente. As relações sociais que se reproduzem nas organizações são econômicas, sociais e ideológicas. A transmissão da ideologia é um fator geralmente negligenciado nas análises organizacionais que tem a empresa por objeto.
* PALAVRAS-CHAVE: Empresas, organizações, ideologia, espetáculo, hegemonia.

* ABSTRACT: Organizations are practical sets oriented to production and reproduction of some social relations wich are necessaries to maintenance and expansion of the more general economic system. The social relations wich are reproducted in organizations are economic, social and ideologycal. Ideologycal transmission is generally neglected in organizational analysis in business.

* KEY WORDS: Entreprises, organizations, ideology, show, hegemony. 


\section{INTRODUÇÃO}

As diversas definições de organização têm um conteúdo descritivo. Mesmo a afirmação de que a organização é um sistema social racional não parece esclarecer o seu caráter funcional. $E$, no entanto, a funcionalidade da organização é fundamental para o seu entendimento. De modo muito amplo, pode-se afirmar que um sistema econômico produz e se reproduz através das organizações. Estas são, portanto, conjuntos práticos voltados para a produção e para a reprodução de determinadas relações sociais necessárias à manutenção e expansão do sistema econômico vigente.

As relações sociais que se reproduzem nas organizações confirmam e reforçam a estrutura social. Essas relações são econômicas, políticas e ideológicas, da mesma forma que os conflitos sociais podem ser sempre analisados a partir dessas três dimensões. A ideologia é uma verdade apenas se a entendermos como verdade conflitual. Isto quer dizer que a ideologia é um conjunto de valores e crenças que visa à manutenção de uma determinada ordem social, ocultando os elementos que a ameaçam e lhe são inerentes.

Todo ordenamento social, de resto toda ação social, pressupõe uma estrutura de sentido que designa os lugares e os papéis dos diversos atores, conferindolhes identidade e submetendo-os a uma determinada forma de dominação. Os atores não são passivos, entretanto, podendo também responder ideologicamente à dominação. Ocorre, porém, que em qualquer sociedade existe uma ideologia dominante, e esta é sempre a ideologia da classe dominante.

A maior parte dos estudos sobre a relação entre a ideologia e as instituições tem privilegiado o aparelho escolar. A escola é vista como a organização que reproduz por excelência as crenças e os valores da classe dominante. A escola é, assim, vista como mecanismo disciplinar, que forma submetendo. Há mesmo estudos interessantes que mostram a existência nas sociedades capitalistas de duas redes escolares, uma para os filhos da classe dominante, outra para os filhos da classe dominada ${ }^{1}$. Sem dúvida, esses estudos parecem esclarecer muito as fun- ções ideológicas da escola. Evidentemente, porém, pouco esclarecem sobre as funções ideológicas da empresa.

Este artigo procurará relatar os resultados de um pequeno número de pesquisas sobre a função ideológica da empresa. Parece-nos que tais pesquisas indicam alguns caminhos interessantes para a análise do tema. Antes, porém, procuraremos situar a questão da ideologia do ponto de vista da sociedade global.

\section{A IDEOLOGIA COMO ESPETÁCULO ${ }^{2}$}

As sociedades onde dominam as modernas condições de produção caracterizam-se pela existência de uma camada ideológica que se concretiza a cada momento vivido e assume o aspecto de um espetáculo. Esse espetáculo implica a reconstrução material de uma ilusão religiosa. Ele tem os seus deuses, mas estes estão em um espaço terrestre, ligados a uma base terrestre. $O$ espaço em que se realiza o espetáculo está sempre contido em um futuro, que anuncia a posse de um produto apresentado como indissoluvelmente ligado à satisfação e ao gozo instantâneo.

A ideologia dominante nessas sociedades tem um sentido e uma coerência que são ilusórios. São ilusórios na medida em que a satisfação que anunciam nunca poderá ser realmente atingida. Essa impossibilidade permanente submete as pessoas a uma sucessão de saltos no vazio. Elas procuram uma coerência e um sentido que na realidade não existem.

É próprio do espetáculo estimular a procura do impossível, distanciando cada vez mais as pessoas de si mesmas. Cada momento vivido da ideologia é a afirmação da aparência. Toda a vida humana é afirmada apenas como aparência. O espetáculo, que é a ideologia dominante se concretizando, reflete a acumulação de capital em grau tão elevado que sua tradução material e sensata é impossível a nível individual. Essa acumulação só existe para o indivíduo como imagem ou como conjunto mais ou menos organizado de imagens.

A ideologia dominante pressupõe a aceitação majoritária de que seus fins são legítimos. Para tanto, ela se concretiza de modo a ser contínua. Todavia, as pessoas
1. ESTABLET, R. \& BAUDELOT, C. La Escuela Capitalista. México, Siglo Veintiuno, 1975.

2. Esse tipo de análise é feito por DEBORD, Guy. A Sociedade do Espetáculo. Lisboa, Afrodite, 1979. 
só a aceitam sob forma de contemplação de um projeto sem objetivos. É por essa razão que os meios, que correspondem à posse dos objetos, aparecem como fins.

A mercadoria funciona como instrumento através do qual o espetáculo se impõe. O fetichismo da mercadoria está na promessa de vida e de prazer que ela traz consigo. Ela não a traz apenas em si mesma, mas também em sua embalagem atraente. Ela se anuncia como conteúdo de vida, como promessa de uma vida que se alimenta de promessas. A mercadoria se apresenta em grande quantidade. O mundo se apresenta como um grande mercado regido pela sociedade dividida em classes.

O próprio trabalho humano se traduz em trabalho-mercadoria. É algo que pode e deve ser trocado. $O$ trabalho humano vendido pode produzir a abundância, mas só permite a sobrevivência ampliada. Essa sobrevivência ampliada se refere às necessidades criadas pela comunicação de massa e pela vida social. Essa sobrevivência não pára de se ampliar.

A ampliação da sobrevivência depende da privação, que é o motor do consumo. Nesse sentido, ela apenas torna a privação mais rica. É dessa forma que a existência se transforma na sobrevivência sob o poder imposto pela mercadoria. Atingido em grau elevado de abundância, o trabalhador pode e deve colaborar com o excedente como consumidor. $O$ valor de troca da mercadoria domina quase completamente o seu valor de uso.

As contradições de ideologia dominante unem-se na base ao sistema universal que as contém: o capitalismo. $O$ poder burocrático faz parte do espetáculo e aparece na divisão mundial das tarefas ideológicas. Nos países capitalistas avançados, a raiz da ideologia burguesa está na economia tornada abundante. Ela se apresenta como imagem nas celebridades criadas pelo sistema, em milionários, reis e rainhas, atores e atrizes etc.

As pessoas em que o sistema se personifica são bem conhecidas por parecerem aquilo que não são. Elas são aquilo que Chico Buarque chama de "a vida mais vivida que vem lá da televisão". É por essa razão que o espetáculo se constrói sobre a miséria do não-vivido.
A ideologia dominante sob a forma de espetáculo pode ser difusa ou concentrada. No capitalismo burocrático, a ideologia é concentrada. Forma-se uma grande burocracia, que detém o trabalho social total. Ela revende esse trabalho à sociedade sob a forma de sobrevivência em bloco. Fica garantida a perpetuação do irracional, a submissão a pseudonecessidades. Fica garantida a universalidade das pseudonecessidades e ocultada a divisão da sociedade em classes.

$\mathrm{Na}$ verdade, a burguesia foi uma classe revolucionária que nunca venceu totalmente. Isto porque ela precisa de um proletariado que também tenha traços burgueses. A burguesia usa o Estado, que tem um papel importante na administração calculada do processo econômico.

É sempre possível a organização do proletariado, mas nem sempre ela é eficiente. É possível que sua ineficiência derive da retomada de métodos centralizadores e hierárquicos tirados de empréstimo do Estado e das empresas. Se o proletariado contém em si o não-poder, ele tem condições de realizar um projeto político autêntico. Isto depende, porém, da negação do espetáculo. Depende das formas históricas assumidas pelo seu projeto, formas essas que não precisam ter sido formuladas pela teoria. São, ao contrário, essas formas que enriquecem $e$ dão vida às teorias.

As antigas sociedades governadas pelo mito tinham uma noção de tempo imutável, de tempo cíclico, como atestam os ritos ligados às estações do ano. As classes detentoras da "propriedade privada" da história criaram a noção do tempo irreversível. Na sociedade feudal, o tempo irreversível era o tempo vivido pela burguesia. $O$ tempo do trabalho, liberto do tempo cíclico, é o tempo ao qual está ligada a burguesia.

É com a burguesia que o trabalho transforma as condições históricas. A burguesia implanta consigo um tempo profundamente histórico. A dominação burguesa coloca toda a sociedade em um mesmo movimento geral. Essa mesma burguesia, que trouxe ao mundo a possibilidade de tempo irreversível, não permite, porém, nenhuma outra forma de emprego deste tempo irreversível. 
A burguesia deseja uma espécie de liberdade: a liberdade generalizada de comércio. De resto, ela quer a passividade da classe dominada, e a consegue parcialmente por meio das instituiçōes que transmitem e inculcam sua ideologia. O mundo construído pela burguesia é um mundo passivo e ordenado e essa é a imagem que é transmitida à sociedade.

O tempo colocado pela ideologia dominante é o tempo do consumo das imagens. Essas imagens são apresentadas como a vida real. Assim, o tempo, sendo ideologicamente inculcado, traduz-se em abandono da história. A consciência do tempo, ao contrário, é a consciência de que o tempo histórico pode ser realmente vivido. É dessa consciência que depende a superação da ideologia dominante.

A sociedade espetacular também apresenta um determinado tipo de ação cultural. A cultura opera em dois sentidos formalmente opostos. Esses dois sentidos, todavia, estão unidos enquanto pensamento submisso. O primeiro sentido é a crítica do espetáculo feita pelo próprio espetáculo. A crítica interna da cultura é unificada, mas procura negar a prática social unificada. Assim, procura-se negar culturalmente a cultura do tempo histórico, isto é, a cultura onde se formulam projetos políticos.

\section{IDEOLOGIA E HEGEMONIA ${ }^{3}$}

A análise marxista, que influenciou a maior parte dos estudos sobre ideologia, ou com a qual outras análises se confrontam, parte da percepção da estrutura social enquanto totalidade. Essa totalidade se manifesta em três esferas: a da produção e distribuição, a jurídica - onde se dão a articulação e a ação política - e aquela propriamente ideológica. Essa percepção impede a visão de cada esfera como autônorna ou não dotada de significado. O objetivo, ao contrário, é analisar as formas pelas quais elas se inter-relacionam em uma formação social concre- ta, isto é, em uma dada sociedade, num dado tempo.

Admite-se que a base real sobre a qual se constrói o jurídico e o político é a esfera econômica ou da produção e distribuição. Daí o nome de superestrutura. A essa superestrutura correspondem determinadas formas de consciência social, ou seja, a ideologia. Em última instância, portanto, são os homens que produzem as suas representações, as suas idéias, a partir de uma dada base material. Em toda ideologia, porém, os homens e suas relações surgem alterados. Por essa razão, não basta partir do que os homens pensam para explicá-los. Deve-se, ao contrário, partir de sua atividade real para explicar seu pensamento.

Nessa perspectiva, torna-se necessário entender o processo de formação da consciência. Marx e Engels entendiam que após a consciência puramente animal do meio sensível imediato, surge para o homem a consciência da necessidade de entabular relações com os que o cercam, marcando para si a consciência de que vive, efetivamente, em sociedade. A consciência vincula-se, portanto, à divisão social do trabalho.

A correspondência da consciência social ou ideologia à base material é essencial à estabilidade de um modo de produção. O desenvolvimento de uma sem o da outra pode ser o prenúncio de um novo modo de produção.

De tudo o que foi dito até o momento, pode-se depreender que a função básica da ideologia é a manutenção da coesão social. Preenche essa função, porém, ocultando o antagonismo básico de um modo de produção, ou seja, sujeitando dominados e justificando dominadores. Como tais relações são transitórias, as ideologias também o são, como atestam teorias sociais que são dominantes em certas épocas, mas nāo em outras.

As ideologias surgem, modificam-se e eventualmente desaparecem, face ao movimento das relaçōes sociais concretas.
3. MOTTA, Fernando C. P. Empresários e Hegemonia Politica. São Paulo, Brasiliense, 1979. 
Para o marxismo, as rupturas não se dão apenas no interior da esfera ideológica. As rupturas mais importantes a nível ideológico decorrem de mudanças na base material. De outro lado, entende-se que em toda sociedade fundada no antagonismo de classe, a emancipação da classe oprimida surge como uma condição vital. É, porém, apenas dotada de uma consciência de classe que ela desenvolve uma ação historicamente significativa, em termos de seus interesses.

O surgimento da consciência de classe acompanha a trajetória de uma classe social. Uma classe que não percebe como atua a totalidade social não pode modificá-la. É uma classe inerte. É, porém, dotada de consciência que uma classe procura impor sua ideologia ao resto da sociedade. Há, portanto, um processo de imposição ideológica dotado de uma determinada anatomia. É nesse particular que se entende a importância das instituições e especialmente dos aparelhos ideológicos de Estado.

Os aparelhos ideológicos contribuem na reprodução das condições de produção. Entre essas condições, situa-se a reprodução de sua força de trabalho, de sua qualificação e de sua sujeição à ideologia dominante. Tal ideologia consubstancia-se em práticas e tais práticas estão presentes nas escolas, na igreja, na indústria da comunicação etc. É nosso ponto de vista que tais práticas também estão presentes em aparelhos econômicos, como a empresa.

O que parece importante frisar é que na forma e sob a forma de sujeição ideológica é assegurada a reprodução da qualificação da força de trabalho. Para que possam agir eficazmente, os aparelhos ideológicos precisam ser controlados pela classe dominante. Esta controla mais facilmente os aparelhos repressivos, dada a própria natureza básica do Estado de servir à classe dominante para a apropriação do excedente. A luta pelo domínio dos aparelhos ideológicos é portanto vital na trajetória de uma classe em ascensão.

Todavia, a ideologia não nasce nos aparelhos ideológicos, mas nas relações entre as classes. Para tornar mais claro o problema da ideologia é preciso considerar que por trás dela está o conflito de classes, o regime político, a tradição na- cional e a herança de uma cultura. Isto quer dizer que para entender a ideologia é preciso fazê-la historicamente e a partir de seu núcleo, que é a divisão social do trabalho.

Assim, não se pode simplificar o conceito de ideologia, identificando-a com o simples discurso da classe dominante. A ideologia deve ser encontrada na ação das classes sobre o Estado, a empresa, a escola e todas as instituições modernas. É preciso notar que a ideologia está sempre a serviço de um projeto, que se traduz em uma prática política. No caso da classe dominante, esta prática pode ser analisada do ponto de vista de uma trajetória. Tendo os aparelhos repressivos do Estado a seu serviço, ela procura controlar os aparelhos ideológicos.

Os elementos organizacional e autoritários têm nesse processo uma função muito grande, tão logo se tenha verificado a orientação da trajetória. A adesão ou não das massas a uma ideologia é o modo pelo qual se verifica o caráter histórico dos modos de pensar. Modos de pensar secundários são mais ou menos rapidamente eliminados pela competição histórica, ainda que consigam gozar de certa popularidade. Ao contrário, construções mentais que correspondem às exigências de um período histórico complexo terminam sempre por prevalecer.

Em qualquer lugar do mundo, a escola e a Igreja são organizações culturais importantíssimas na transmissão da ideologia. Deve-se ainda lembrar os jornais, a televisão, as revistas, os partidos políticos e todas as instituições. Há ainda a ideologia inculcada através das profissões, que correspondem a frações não desprezíveis da cultura. É o caso dos médicos, dos oficiais do exército e da magistratura.

Apesar de tudo o que foi dito, não é difícil perceber uma cisão entre os grupos de intelectuais e as massas populares. Isto ocorre porque o Estado, ainda que os governantes digam o contrário, não tem uma concepção unitária, coerente e homogênea. Ainda assim, é evidente que o que se procura é a obtenção coletiva de um mesmo clima cultural. A realização desse clima se dá através do homem coletivo, que reúne uma multiplicidade de vontades desagregadas e de fins heterogêneos, que se solidificam na busca de 
um mesmo fim sobre a base de uma concepção comum do mundo.

Quando uma classe consegue a realização desse clima na sociedade, ela é uma classe hegemônica. É por essa razão que toda relação de hegemonia é necessariamente uma relação pedagógica. Pode-se entender assim a necessidade da liberdade de pensamento e de expressão, já que só onde existe essa condição política se realiza a relação pedagógica no sentido mais geral.

Uma classe social que não consegue afirmar-se ideologicamente não é uma classe hegemônica. Por sua vez, a realização da hegemonia determina uma reforma das consciências e dos métodos de conhecimento. Assim, toda concepção dominante tern por tarefa a conservação da unidade ideológica de todo o bloco social, que por natureza não é hegemônico. É óbvio que a heterogeneidade do bloco social está fundamentada em contradiçôes de classe que a ideologia procura negar.

De modo mais geral, podemos afirmar que uma classe é hegemônica, dirigente e dominante à medida que, por meio das ações cultural e ideológica, traduzidas em ação política, consegue manter as forças conflitantes e heterogêneas de tal forma articuladas que os antagonismos não levam à recusa da ideologia por essas forças.

A hegemonia pode ser assim entendida como o controle ideológico da sociedade por uma classe, uma fração de classe ou uma aliança de classes. A ideologia da classe dominante corresponde à sua função histórica e aos seus interesses. Trata-se de descer até as classes subalternas. Um grupo social que é dirigente de seus grupos afins e aliados tem uma das condições básicas para a conquista do poder.

Dessas considerações se depreende a posição orgânica do intelectual na sociedade. Não é difícil constatar que na sociedade capitalista esses intelectuais têm no
Estado e na empresa a sua razão de ser. Eles são geralmente responsáveis pelo planejamento em sentido amplo. Os empresários precisam pelo menos de uma elite própria, dotada da capacidade de organizar a sociedade. Podem funcionar, assim, como prepostos dos empresários. $\mathrm{O}$ projeto hegemônico burguês precisa, dessa forma, da criação de uma nova cultura ${ }^{4}$.

\section{O ESPAÇO DA EMPRESA}

Muito pouco se tem escrito sobre a transmissão da ideologia na empresa. Assim, é nosso objetivo aqui apresentar um sumário de algumas pesquisas importantes no campo. O primeiro deles é um estudo sobre uma grande empresa multinacional, realizado por Pagés, Bonetti, Gaulejac e Descendre. ${ }^{5}$

As conclusōes da referida pesquisa levam à visão da organização como um conjunto de produtos de contradições entre empresas, entre estas e o Estado, bem como entre empresa e trabalhadores e entre sistemas sociais de desenvolvimento desigual. A particularidade da organização estaria na oferta de soluções mediadoras para contradições de ordem econômica, política, ideológica e psicológica.

A mediação da organização se faria, segundo os pesquisadores, em quatro níveis. $O$ primeiro nível, o econômico, referir-se-ia à questão dos lucros e dos salários. $\mathrm{O}$ segundo nível diria respeito à questão da autonomia e do controle, sendo um nivel propriamente político. Oterceiro nível estaria relacionado à questão do humanismo e da eficiência, constituindo um nível ideológico. $O$ último e quarto nível diria respeito ao prazer e à angústia, apresentando-se como especificamente psicológico.

O mecanismo básico da operação da empresa seria a transformação das contradições coletivas em contradições individuais. Todas as contradições econômicas, políticas e ideológicas seriam trans-
4. Tais idéias acham-se desenvolvidas em diversos autores marxistas. Ver principalmente, MARX, Karl \& ENGELS, Friedrich. A ldeologia alemā; Lisboa/SP, Editorial Presença/Livraria Martins Fontes, s/d; ALTHUSSER, Lauis. "Ideology and ideological state apparatuses." In Lenin and Filosophy and other essays. Monthly Review Press, EUA, 1971; GRAMSCI, Antonio. Concepção Dialética da História. Rio de Janeiro, Ed. Civilização Brasileira, 1978.

5. PAGÉS, Max: BONETTI, Michel; GAULEJAG, Vincent de \& OESCENDRE, Daniel. L'Emprise de I'Organisation. Paris, PUF. 1979. 
formadas em contradições meramente psicológicas. Esse mecanismo de conversão caracterizaria um processo pelo qual a organização apoderar-se-ia de seus membros.

Dito de outra forma, a organização realizaria políticas mediadoras em quatro níveis de atuação: econômico, político, ideológico e psicológico. Em relação a seus membros, ela ofereceria em cada um desses niveis, respectivamente: salários e carreira, autonomia, humanismo e sedução e prazer. Em contrapartida, ela exigiria a submissão ao lucro e à expansão, ao controle à eficiência, e acenaria com a ameaça e a angústia. As contradições sociais seriam pouco a pouco convertidas em contradições psicológicas, isto é, em confronto de ameaças e angústia com sedução e prazer.

A constatação fundamental dos pesquisadores é a de que os indivíduos isolados apresentam-se como impotentes para lutar contra suas próprias contradições, não lhes sendo possível o estabelecimento de uma cooperação verdadeira. Assim sendo, esses indivíduos aceitam as soluções prontas oferecidas pela organização, introjetando seus princípios, seus tipos de prazer e ameaça. A empresa apresenta-se, portanto, como uma solução global aos problemas da existência humana, obtendo uma enorme parcela de seu poder do fato de oferecer uma resposta às contradições psicológicas individuais e interindividuais.

A conquista ideológica dos empregados pela empresa parece basear-se no fato de que esta oferece uma interpretação do real relativamente coerente com as práticas sociais dos indivíduos, fornecendo-lhes uma visão de mundo coerente com as suas aspirações. Os pesquisadores vêem a ideologia da empresa como uma religião secularizada, considerando que a falência das religiões tradicionais no cumprimento das mesmas funções é provocada pela sua incapacidade de traduzir no plano espiritual a vivência cotidiana da sociedade industrial. Dessa forma, a empresa criaria uma religião melhor aceita pelos seus membros. Para tanto, a empresa se basearia em um conjunto de crenças formando um dogma, em escrituras sagradas e ritos práticos, em uma or6. Idem, ibidem. em uma massa de fiéis comungando na mesma fé e na existência de um deus encarnado pela organização.

As crenças partilhadas pelos membros da empresa incidiriam em cinco aspectos centrais. Em primeiro lugar, o consenso quanto à busca do progresso técnico; em segundo, o ideal de realização pessoal no trabalho; em terceiro, a crença na igualdade de oportunidades de promoção; em quarto, a crença nas recompensas pelos esforços por parte da organização e, finalmente, a busca do sucesso individual. Tudo isso estaria de certa forma enquadrado em um ordenamento básico que consiste em servir aos clientes, aos empregados, aos acionistas e ao mundo. Nesse conjunto de crenças, os indivíduos encontram princípios em que podem acreditar, que lhes permitem atribuir sentido a suas existências. A força desse sistema provém da coerência interna das crenças e de sua correspondência com a realidade vivida cotidianamente.

Pagés e seus colaboradores acreditam que a organização é armada pelos seus membros pelas perfeições que estes individualmente desejam para o seu próprio ego $^{6}$. O objetivo introjetado toma o lugar do ideal do ego. Dessa forma, a organização é o lugar da formação do inconsciente, que passa a ser uma realidade coletiva. Aqui, torna-se importante a distinção entre superego e ideal do ego. $O$ primeiro representa, no inconsciente individual, a repressão social ligada à transgressão de proibições. $O$ superego contém uma ameaça da castração pela figura paterna. O segundo, o ideal do ego, contém uma ameaça de perda do amor materno.

Os pesquisadores entendem que a economia feudal representa um modelo dominado pelo superego e a economia capitalista nascente representa um modelo hibrido de dominação do superego e do ideal do ego. Já a economia capitalista de organizações hipermodernas (grandes empresas multinacionais) apresentaria uma dominação do ideal do ego. Nesta situação, dá-se a passagem da obediência a um chefe à adesão a uma lógica, as regras são concebidas de forma a estruturar o espaço no qual são tomadas as decisões e, ao nível da aplicação, são inculcados hábitos de obediência.

Nesse sentido, o sentimento de culpa 
não surge mais do fato de cometer um ato contrário à consciência, às exigências do superego, mas do fato de não estar à altura das exigências da organização e do ideal que o trabalhador procura atingir. A expressão "você deve" é substituída por "é preciso". A nível propriamente ideológico, a empresa hipermoderna produz uma religião interna própria, criando e disseminando sentidos e valores. Ao nível mais propriamente psicológico, a empresa conquista os trabalhadores fazendo com que os conflitos por ela sentidos sejam reconhecidos como de origem estritamente psicológica, impossibilitando qualquer ação de mudança. A pesquisa relatada mostra bem as funçōes da ideologia: fazer crer, fazer amar e fazer agir. A organizaçāo passa a ser para seus membros o objeto de um grande amor e um grande temor, que garantem o comportamento adequado aos interesses da cúpula administrativa.

Outros trabalhos interessantes são os de Michel Villete, Luc Boltanski e J.C. Poitou ${ }^{7}$.Apresentando-os em linhas gerais, iniciamos pelo texto "Psicossociologia da empresa e reeducação moral", passando por "Os executivos autodidatas", por "O acesso às posições dominantes na empresa" e chegando, finalmente, ao texto "A imprensa patronal na grande empresa". São estudos independentes, muitas vezes ainda em fase preliminar, mas que podem dar uma primeira visão do tema.

O texto "Psicossociologia da empresa e reeducação moral", de Michel Villette, trata do desenvolvimento da socialização através do treinamento8. De início, vale a constatação de que o treinamento é utilizado pelas empresas no desenvolvimento das qualificações necessárias ao desempenho das diversas funções. O treinamento opera em dois níveis, sendo que apenas o primeiro diz respeito mais diretamente às habilidades técricas ligadas ao exercício da função. O segundo nível, mais propriamente ideológico, refere-se à internalização pelos membros da empresa de determinados comportamentos necessários. Esses comportamentos contribuem para a mudança da imagem que os indivíduos têm de si próprios.

O treinamento, com o objetivo de mudança de imagem, fica bem caracterizado no texto, que trata de seminários voltados para a interiorização das censuras institucionais contra comportamentos espontâneos, inadequados à situação empresarial, bem como para o ensinamento do desempenho de um novo papel. O caso estudado por Villette se refere a um seminário destinado a elementos de nível intermediário, geralmente detentores de posições de comando ou com características potenciais para ocupar futuras posições de chefia9.

A inscrição de seus membros, por parte da empresa, em seminários desse tipo, parece estar ligada à necessidade de mudança nas formas de exercício do poder no âmbito da empresa. Há, aparentemente, um desejo das empresas de harmonizar os comportamentos dos ocupantes de chefias intermediárias. Tais comportamentos se apresentam muito diferentes de acordo com características individuais. Assim, origem sócio-econômica, cultural ou formação educacional rígida podem resultar em inadaptações nos hábitos. Deste modo, origem social muito baixa perante os superiores e familiaridade excessiva em face dos subordinados configuram uma situação que deve ser corrigida. Os seminários visam a corrigir essas disparidades, promovendo a socialização desejadaio.

O texto de Boltanski diz respeito às oportunidades de carreira ${ }^{11}$. A tônica do trabalho é sobre o papel do capital social e cultural dos indivíduos nessas oportunidades. Por capital social e cultural entende-se tanto as origens econômicas e sociais quanto a formação adquirida em escolas de elite. As posições dominantes da empresa, ou seja, os cargos de alta administração parecem ser de difícil acesso,
7. VILLETTE, Michel. "Psicossociologia da Empresa e Reeducaçāo Moral". São Paulo, EAESP/FGV. (Mimeo.) Traduzido por Denice Barbara Catani de Actes de la Recherche en Sciences Sociales. Paris, (4):47-65, ago. 1976, de acordo com seleção e indicação do Prof. Josés Carlos Garcia Durand. BOLTANSKI, Lee. "Os executivos Autodidatas". Sāo Paulo, EAESP/FGV. (Mimeo.). Traduzido por Denice Barbara Catani, por indicaçāo do Prof. José Carios Garcia Durand, de Actes de la Recherche en Sciences Sociales, Paris, (22), jun. 1978, e publicado na Revista de Administração de Empresas, FGV, 24(1):5-25, jan-mar 1984

8. VILLETE, Michel. Op. cit.

9. Idem, ibidem.

10. Idem, ibidem.

11. BOLTANSKI, Lee. Op. cit. 
12. Idem, ibidem.

13. VILLETTE, Michel. "0 acesso às posições dominantes na empresa". São Paulo, EAESP/FGV (Mimeo.) Traduzido, por José Carlos Garcia Durand, de Actes de la Recherche em Sciences Sociales. Paris, (4), jul. 1975.

\section{Idem, ibidem}

15. Idem, ibidem. restringindo-se o seu recrutamento a um grupo relativamente pequeno e fechado. Como conseqüência, os administradores de nível médio não sabem até onde podem chegar, nem mesmo conhecendo bem a amplitude de sua autoridade e de sua autonomia. A possibilidade de conhecerem seus limites é dada pelo processo de socialização, especialmente pelos seus contatos com detentores de capital social e cultural mais elevado.

Os administradores de nível médio são, principalmente, treinados no trabalho, o que significa aprender muito mais do que um ofício ou um conjunto de funções. Na realidade, seu treinamento consiste, em larga escala, na interiorização dos valores dominantes no mundo empresarial. Esse processo pode ser razoavelmente doloroso, na medida em que incorpora visões estereotipadas da vida cotidiana e conflitos entre posição de classe e pertencimento de classe, na medida em que a identidade desejada não corresponde à identidade original.

A investigação de Boltanski indica a criação de um tipo particular de indivíduo, no universo empresarial12. $\mathrm{O}$ homem organizacional é na verdade o homem unidimensional de Marcuse, $o$ indivíduo que não distingue realidade e aparência, fenômeno e essência. Essa "consciência feliz" seria portanto um estado de alienação, no qual o divórcio entre comportamento dramatúrgico e personalidade não seria algo consciente, mas o resultado de um esforço quase compulsivo em ser o que não se é.

$\mathrm{O}$ trabalho "O acesso às posições dominantes na empresa", de Michel Villette, trata da forma pela qual os filhos de famílias já privilegiadas garantem para si os cargos mais importantes na hierarquia das empresas francesas ${ }^{13}$. A questão se coloca uma vez que a ideologia dominante apregoa que indivíduos com habilidades técnicas semelhantes, independentemente de sua origem social e cultural, possuem oportunidades iguais de acesso às posições dominantes. Esse tipo de raciocínio amplia-se pela idéia de que o acesso às escolas melhores, onde se transmite essas qualificações técnicas, também é igual para todos.

Permanece porém o fato de que os chamados filhos-família são na maioria dos casos aqueles que efetivamente chegam às posições mais altas em menos tempo. Villette constata que a questão passa por uma estratégia de inovação, baseada em um deslocamento permanente do prestígio e do peso relativo das diversas funções ${ }^{14}$. Dito de outra forma, é preciso que o capital sócio-cultural se transforme em competência rara, legitimando as promoções. O movimento, portanto, implica que uma nova competência se valorize porque é rara, porque foi escolhida pelos filhos-família e porque é útil em um determinado momento, bem como no fato de os filhos-família terem adquirido um monopólio de tal competência, tornando-se os únicos a terem experiência prática e global dos novos métodos.

Há, pois, uma aliança família-empresa-escola de elite que se articula para o acesso de pessoas dotadas de capital social e cultural aos postos dominantes. Também alguns cursos ou graus de pósgraduação no exterior, principalmente nos EUA, podem participar desse tripé. A estratégia não é, de qualquer forma, conduzida de um só golpe. As especializações constituem-se em simples "trampolins" para as posições dominantes. Os detentores de capital sócio-cultural perdem tempo absoluto para ganhar tempo relativo. Tudo se passa de forma natural, como se fosse resultado de imposições do meio, isto é, apenas como resultado do progresso técnico que impõe às empresas as inovações necessárias à concorrência inter-capitalista. 15

Uma outra linha interessante de análise de transmissão ideológica da empresa refere-se a seu sistema de comunicações e em especial aos jornais de empresa. $\mathrm{Na}$ Europa, o jornal da empresa está relacionado com o crescimento e o desenvolvimento das empresas industriais a partir do início deste século, bem como à organização crescente da classe operária no mesmo período.

Segundo Jean-Claude Poitou, autor de um trabalho intitulado "A imprensa patronal na grande empresa", o jornal patronal significa uma tentativa de neutralização dos conflitos entre objetivos de empregadores e empregados em uma época de aumento quantitativo de bens produzidos, de concentração de capital e de 
parcelamento das tarefas, com a conseqüente desqualificação da mão-de-obra. ${ }^{16}$

Em um primeiro momento, o jornal patronal teve por função explorar três temas básicos: o que deve e como deve fazer o "bom operário", a valorizaçāo de realizações paternalistas da direção das empresas, e a justificação do taylorismo como a melhor forma de produção. Após a II Guerra Mundial, com o advento da escola de relações humanas, as empresas mudam sua linha editorial, incluindo reportagens para as famílias dos trabalhadores, divulgação de obras sociais, bem como artigos sobre legislação e notas do departamento de pessoal.

No caso francês, 1968 parece ser um novo marco. A partir dessa data, os empresários viram-se obrigados a repensar os métodos de integraçāo entre capital e trabalho. O jornal da empresa é chamado, então, a desempenhar seu papel e algumas orientações gerais passam a ditar sua linha editorial. Sublinha-se a difusão do sentimento de afiliaçẫo do empregado à empresa fazendo transparecer que os objetivos individuais são iguais ou semelhantes aos objetivos da empresa, procurando o consenso e a coesão dos esforços. Paralelamente, procura-se desenvolver a criatividade, mediante um esclarecimento mais intensivo da oportunidades de carreira. Entende-se, ainda, que é função da informação na empresa garantir a melhor qualidade da decisão em cada escalão da hierarquia. É dessa época a divulgação aos empregados de seu posicionamento no mercado, de dados sobre a qualidade dos produtos da empresa, de demonstrações financeiras, bem como a publicação de artigos dos empregados em geral, ou por área funcional, e de artigos diversos sobre esporte, etiqueta, saúde, previdência etc. No plano gerencial, é a época da administração por objetivos.

Uma constante nos jornais de empresa parece ser, ainda, a divulgação de preços e vantagens oferecidos pela cooperativa de consumo, o elogio sistemático dos "operários-padrão", como modelo para todo o operariado da empresa, a divulgação de possibilidades de cursos oferecidos pela própria empresa ou outros órgãos, úteis na carreira do operário, bem como informações sócio-culturais gerais.

Em síntese, o objetivo desse artigo foi mostrar uma área ainda pouco explorada na teoria das organizações, mas indiscutivelmente importante na prática administrativa e no comportamento humano na empresa. Tudo leva a crer que o estudo sistemático das funçōes ideológicas da empresa explique bastante decisões e aspectos que à primeira vista padecem de sentido, bem como a forma pela qual os indivíduos vêm-se relacionando com as organizações, desenvolvendo um tipo de personalidade, e experimentando e lidando com novas formas de angústia e de satisfação. A análise de qualquer instituição que năo passe pelo nível ideológico é sempre incompleta, purque se limila ao imediatamente visível, quando geralmente o importante está naquilo que permanece oculto. $\square$

\section{BIBLIOGRAFIA SUPLEMENTAR}

ALVESSON, Mats. Organization Theory and Technocratic Consciousness, Berlim, De gruyter, 1987.

ENRIQUEZ, Eugene. L'Organisation en Analyse. Paris, PUF, 1992.

ENRIQUEZ, Eugene. Les Figures du Maitre. Paris, Arcantère, 1991.

MORGAN, Gareth. Images of Organization. Londres, Sage Publication, 1989.
16. POITOU, Jean-Claude. "La presse patronale dans la grande entreprise". Economie Politique. Paris, (206), set. 1971. 